\section{Referenzmaterials, Austauschbarkeit eines}

C. Vidal ${ }^{1}$ und W.-R. Külpmann ${ }^{2}$

${ }^{1}$ Landeskriminalamt Niedersachsen, Dezernat 53 „Chemie“, Hannover, Deutschland

${ }^{2}$ Hannover, Deutschland

Englischer Begriff commutability of a reference material

Definition Eigenschaft eines Referenzmaterials, nachgewiesen durch das Ausmaß der Übereinstimmung von Messergeb- nissen (s. > Messergebnis) für eine angegebene Größe dieses Materials, erhalten durch zwei vorgegebene $>$ Messverfahren, und der Beziehung zwischen den Messergebnissen für andere spezifizierte Materialien (Brinkmann 2012). Für Anmerkungen s. Literatur.

\section{Literatur}

Brinkmann B (2012) Internationales Wörterbuch der Metrologie (VIM) Deutsch-englische Fassung. ISO/IEC-Leitfaden 99:2007, 4. Aufl. Beuth-Verlag, Berlin 